\title{
The Effectiveness of Triple Fixed-Dose Combination Therapy in the Management of Uncontrolled Arterial Hypertension
}

\author{
Shukhrat M. Masharipov, PhD; Khurshid Kh. Ataniyazov; \\ Dilafruz Yu. Shukurova; Gulnoz A. Khamidullaeva, PhD, ScD*; \\ Guzal J. Abdullaeva, PhD, ScD; Ravshanbek D. Kurbanov, PhD, ScD \\ Republican Specialized Centre of Cardiology \\ Tashkent, Uzbekistan
}

\begin{abstract}
The aim of our study was to identify patients with uncontrolled hypertension who were resistant to previous antihypertensive therapy and to assess the clinical efficacy of the fixed-dose triple combination therapy during 6 months.

Methods and Results: The study included 156 patients with uncontrolled hypertension. The mean age of patients was $57.81 \pm 10.8$ years; the average duration of arterial hypertension was $8.87 \pm 5.34$ years. According to the questionnaire data, all patients received dual or triple free-combination antihypertensive therapy, but did not reach the target blood pressure level. After the screening stage, all patients were discontinued from previous therapy and assigned to the fixed-dose triple combination therapy. Patients initially taking angiotensin-converting enzyme inhibitors $(n=96 / 61.5 \%)$ were switched to single-pill triple combination of perindopril, indapamide and amlodipine (Per/Ind/Aml [5mg/1.25mg/5mg]). Patients initially taking angiotensin receptor blockers $(\mathrm{n}=60 / 38.5 \%)$ were switched to single-pill triple combination of telmisartan, hydrochlorothiazide and amlodipine (Tel/HCTZ/ Aml $[40 \mathrm{mg} / 12.5 \mathrm{mg} / 5 \mathrm{mg}])$. Since the purpose of our study was not to compare the effectiveness of 2-drug regimens based on angiotensin-converting enzyme inhibitor or angiotensin receptor blocker, we combined all patients into one group and monitored the dynamics after 3 months and 6 months of treatment.

The primary target level for systolic blood pressuer (SBP) and diastolic blood pressure (DBP) was $<140 \mathrm{mmHg}$ and $<90$ $\mathrm{mmHg}$, respectively. With good tolerability of therapy, we aimed for the recommended target level of SBP/DBP $(<130 \mathrm{mmHg} /<80$ $\mathrm{mmHg}$ ).

All patients underwent the following examinations: assessment of traditional risk factors, physical examination, clinical and biochemical laboratory methods, 12-lead ECG, echocardiography, pulse contour analysis, and 24-hour ambulatory blood pressure monitoring.

The results of our study showed that the fixed-dose triple combination therapy at the indicated initial doses in patients with uncontrolled hypertension made it possible to achieve the primary target blood pressure level in $73.7 \%$ of patients after 3 months of treatment. A further increase in single-pill triple combination doses made it possible to increase the number of patients (after 6 months of treatment) who achieved the primary goal to $92.3 \%$, and the recommended goal in $82.4 \%$ of patients. After 6 months of treatment, against the background of selected doses of single-pill triple combination, $7.7 \%$ of patients were diagnosed with treatment-resistant hypertension.

The echocardiography data showed a significant decrease in left ventricular mass index by $-9.7 \pm 7.3 \%$ after the 3 -month treatment. After 6 months of treatment, there was a further decrease in left ventricular mass index up to $-13.5 \pm 10.1 \%$, while $34 \%$ of patients had no left ventricular hypertrophy, according to left ventricular mass index. After the 6-month treatment, left ventricular hypertrophy remained in $65.4 \%$ of patients versus $89.7 \%$ before starting therapy. The 6-month dynamics of the left ventricular diastolic dysfunction indicator also slightly improved; the left ventricular diastolic dysfunction was not determined in $25 \%$ patients.

A retrospective analysis of the hemodynamic data of patients before treatment revealed significantly high indicators for the office SBP, DBP, and pulse pressure, the central SBP, pulse wave velocity, the average daily, daytime and nighttime SBP, and a higher left ventricular mass index and left ventricular diastolic dysfunction in patients with uncontrolled hypertension than in patients who achieved target blood pressure levels after 3 months of therapy

Conclusion: Markers of uncontrolled hypertension are high SBP, DBP, and increased pulse wave velocity, which requires the maximum doses of a full-dose single-pill triple combination of antihypertensive drugs (Per/Ind/Aml or Tel/HCTZ/Aml), without wasting time on titration of drug doses. (International Journal of Biomedicine. 2020;10(4):334-341.)
\end{abstract}

Key Words: uncontrolled hypertension • antihypertensive drug • fixed-dose triple combination $\bullet$ treatment-resistant hypertension 


\section{Abbreviations}

AH, arterial hypertension; ABPM, ambulatory blood pressure monitoring; AHD, antihypertensive drug; AHT, antihypertensive therapy; ACEIs, angiotensin-converting enzyme inhibitors; ARBs, angiotensin receptor blockers; BP, blood pressure; $\mathbf{C C B s}$, calcium channel blockers; DBP, diastolic BP; DBPc, central DBP; FDTC, fixed-dose triple combination; LVMI, left ventricular mass index; LVH, left ventricular hypertrophy; LVDD, LV diastolic dysfunction; PWV, pulse wave velocity; PP, pulse pressure; PPc, central PP; RAAS, renin-angiotensin-aldosterone system; SBP, systolic BP; SBPc, central SBP; SPTC, single-pill triple combination; TRH, treatment-resistant hypertension; T2DM, type 2 diabetes mellitus; $\mathbf{U C H}$, uncontrolled hypertension.

\section{Introduction}

Arterial hypertension $(\mathrm{AH})$ remains an urgent problem in clinical medicine, being a serious risk factor for cardiovascular complications. $\mathrm{AH}$ has a widespread prevalence among the world's adult population. The STEPS study, conducted in Uzbekistan in 2014, showed a high prevalence (30.8\%) of hypertension among adults 18-64 years old. However, it should be noted that this study did not cover patients over age 65, among whom, according to epidemiological data, the prevalence of hypertension increases 2 or more times, compared to younger people. ${ }^{(1,2)}$

Despite the widespread clinical introduction of combination antihypertensive therapy (AHT), in some patients blood pressure (BP) cannot be controlled, and treatment-resistant hypertension (TRH) is revealed. Predictors of insufficient BP control are old age (over age 75), left ventricular hypertrophy (LVH), obesity, $\mathrm{SBP}>160 \mathrm{mmHg}$, type 2 diabetes mellitus (T2DM), increased consumption of salts, and obstructive sleep apnea. Currently, uncontrolled hypertension ( $\mathrm{UCH})$ is increasing throughout the world, which is associated with a decrease in target BP levels, with an increase in population life expectancy, a more frequent incidence of co-morbid pathology, and insufficient control of cardiovascular risk factors. ${ }^{(3)}$ Of no small importance is the wrong choice or dosage of antihypertensive drugs (AHDs), the lack of synergy of action when using a combination of drugs or irrational AHD combinations, and problems associated with adherence to treatment. These data are worrisome because there is strong evidence of the practical importance of lowering BP to the target level, which results in a reduction in the risk of myocardial infarction by $20 \%-25 \%$, heart failure by $50 \%$ and stroke by $35 \%-40 \%{ }^{(4)}$ One of the forms of UCH is TRH, in which, despite the long-term use of $\geq 3$ AHDs with different mechanisms of action, including diuretics, excessive sodium reabsorption remains in the distal segments of the patient's nephron, which is caused by increased aldosterone activity and hyperactivity of the sympathetic nervous system. ${ }^{(5)}$

According to current recommendations, the first step in choosing AHT is a dual-combination of AHDs, one of which is an RAAS blocker, and the other a calcium channel blocker (CCB) or a diuretic, preferably in a single pill. The choice of a dual-combination AHT at the start of hypertension treatment provides complete control of BP and protection of target organs. In case there is resistance to the dual-combination $\mathrm{AHT}$, it is recommended to switch to a triple combination AHT, consisting of angiotensin-converting enzyme inhibitor (ACEI)/angiotensin receptor blocker (ARB), CCB and diuretics, also preferably in a single pill, in order to increase patient adherence to therapy. According to epidemiological studies, $10 \%-12 \%$ of patients with $\mathrm{AH}$ are resistant to the fixeddose triple combination (FDTC) therapy, which indicates the presence of TRH and requires the addition of the fourth AHD. As a fourth drug, the use of spironolactone, beta-blockers, alpha-blockers or other AHD is recommended. ${ }^{\left({ }^{(}\right)}$

The aim of our study was to identify patients with UCH who were resistant to previous AHT and to assess the clinical efficacy of the FDTC therapy during 6 months.

\section{Materials and Methods}

The study was carried out in compliance with Ethical Principles for Medical Research Involving Human Subjects, Adopted by the 18th WMA General Assembly, Helsinki, Finland, June 1964, and amended by the 64th WMA General Assembly, Fortaleza, Brazil, October 2013 The study protocol was reviewed and approved by the Ethics Committee of the Republican Specialized Centre of Cardiology. All participants provided the written informed consent.

The study included 156 patients with UCH. The mean age of patients was $57.81 \pm 10.8$ years; the average duration of $\mathrm{AH}$ was $8.87 \pm 5.34$ years.

Exclusion criteria were symptomatic hypertension; valvular heart disease, acute coronary syndrome, chronic heart failure (NYHA FC $>\mathrm{III}$ ), cardiac arrhythmia, history of stroke and myocardial infarction within previous 12 months, occlusive peripheral arterial disease, renal impairment, severe co-morbidities, orthostatic hypotension.

According to the questionnaire data, all patients received dual or triple free-combination AHT, but did not reach the target BP level. After the screening stage, all patients were discontinued from previous therapy and assigned to the FDTC therapy. Patients initially taking ACEIs $(\mathrm{n}=96 / 65.8 \%)$ were switched to single-pill triple combination (SPTC) of perindopril, indapamide and amlodipine (Per/Ind/Aml $[5 \mathrm{mg} / 1.25 \mathrm{mg} / 5 \mathrm{mg}]$ ). Patients initially taking ARBs ( $\mathrm{n}=60 / 34.2 \%)$ were switched to SPTC of telmisartan, hydrochlorothiazide and amlodipine (Tel/ HCTZ/Aml [ $40 \mathrm{mg} / 12.5 \mathrm{mg} / 5 \mathrm{mg}])$. Since the purpose of our study was not to compare the effectiveness of 2-drug regimens based on ACEI or ARB, we combined all patients into one group and monitored the dynamics after 3 months and 6 months of treatment.

The effectiveness of therapy was assessed by achieving the target BP level according to $2018 \mathrm{ESH} / \mathrm{ESH}$ Guidelines for the management of AH. The primary target level for SBP and DBP was $<140 \mathrm{mmHg}$ and $<90 \mathrm{mmHg}$, respectively. With good tolerability of therapy, we aimed for the recommended target level of SBP/DBP $(<130 \mathrm{mmHg} /<80 \mathrm{mmHg})$.

All patients underwent the following examinations: assessment of traditional risk factors, physical examination, 
clinical and biochemical laboratory methods, 12-lead ECG, echocardiography, and 24-hour ABPM. Office BP was measured using a mercury sphygmomanometer, according to Korotkov's method. BP was measured 3 times, and the means of these measurements were used in the analyses. The 24-hour ABPM was performed using a BR-102 plus (SCHILLER, Switzerland).

The pulse contour analysis was carried out using the SphygmoCor device (AtCor Medical, Australia), which obtains peripheral arterial pressure waveforms by applying an arterial applanation tonometer to the wrist. The tonometer partially compresses the radial artery and records a pressure wave over several cardiac cycles. This pressure wave is calibrated to brachial cuff blood pressure measurements. The averaged peripheral waveform is then converted to an ascending aortic waveform using a generalised mathematical transfer function. In addition, such indicators as the central SBP (SBPc), central DBP (DBPc), central PP (PPc), and PWV were taken into account.

Echocardiography was carried out according to the recommendations of the American Society of Echocardiography ${ }^{(7)}$ in M- and B-modes using Philips EnVisor C Ultrasound Machine (the Netherlands). The following parameters were measured and calculated: IVST, PWT, LVEDD, LVESD, EF, LVEVD, LVESV, and LVM (LVM was calculated using the formula R. Devereux.$^{(8)} \mathrm{LVM}$ was indexed to body surface area (LVMI). Left ventricular hypertrophy (LVH) was defined as LVMI of $>95 \mathrm{~g} / \mathrm{m}^{2}$ (for women) and $>115 \mathrm{~g} / \mathrm{m}^{2}$ (for men). ${ }^{(6)}$

The ratio of peak early filling velocity to peak atria 1 filling velocity (PE/PA) was calculated. The isovolumic relaxation phase (IRP) was also measured.

Statistical analysis was performed using the statistical software «Statistica». (v6.0, StatSoft, USA). Baseline characteristics were summarized as frequencies and percentages for categorical variables and as mean \pm standard deviation (SD) for continuous variables. Student's paired t-test was used to compare two groups for data with normal distribution. Group comparisons with respect to categorical variables were performed using chi-square test. A probability value of $P<0.05$ was considered statistically significant.

\section{Results}

Among $156 \mathrm{UCH}$ patients, increased body weight and obesity were found in $147(94.2 \%)$ patients, smoking in $51(32.7 \%)$, T2DM managed without insulin in 21(13.5\%), coronary heart disease (FC I-II) in 55(35.2\%), and dyslipidemia in $129(82.7 \%)$ patients. LVH and LVDD were detected in $140(89.7 \%)$ and $128(82.1 \%)$ patients, respectively (Table 1$)$.

Thus, all UCH patients had a high or very high risk of cardiovascular complications. The targeted lifestyle modifications were recommended for all patients. For patients with dyslipidemia, atorvastatin was recommended at a dose of $20 \mathrm{mg} /$ day. Patients with a history of coronary heart disease and T2DM received acetylsalicylic acid.

After 3 months of the FDTC therapy at the indicated initial doses, we noted in the group as a whole a significant decrease in the office SBP by $-20.1 \pm 7.52 \%$, DBP by $-17.7 \pm 8.67 \%$, as well as a significant decrease in the central SBP and DBP and an improvement in the 24-hour ABP profile (Table 2). The primary target level of SBP/DBP was reached in $115(73.7 \%)$ patients. Of these, $82(52.5 \%)$ reached the recommended target SBP/DBP level after 3 months of therapy. At the same time, 41(26.3\%) patients did not reach the primary target BP level at the initial doses of SPTC, which required an increase in the dose of drugs to the maximum tolerable: Per/Ind/Aml - 10mg/2.5mg/10mg, and Tel/HCTZ/ $\mathrm{Aml}-80 \mathrm{mg} / 25 \mathrm{mg} / 10 \mathrm{mg}$, respectively. Patients given a highdose combination of Per/Ind/Aml (10mg/2.5mg/10mg) took 1 pill once a day. Due to the lack of a high-dose combination of Tel/HCTZ/Aml in the pharmacological market, 2 pills of $40 \mathrm{mg} / 12.5 \mathrm{mg} / 5 \mathrm{mg}$ once a day were prescribed. Patients who achieved the primary target SBP/DBP levels continued therapy with the previous doses of FDTC of AHDs.

Table 1.

Clinical characteristics of patients with uncontrolled hypertension

\begin{tabular}{|l|c|}
\hline Variable & General group $(\mathrm{n}=156)$ \\
\hline Age, years & $57.81 \pm 10.8$ \\
\hline Average duration of AH, years & $8.87 \pm 5.34$ \\
\hline BMI, kg/m ${ }^{2}$ & $31.7 \pm 4.58$ \\
\hline Waist circumference, cm & $98.87 \pm 9.74$ \\
\hline Gender: & $88(56.4 \%)$ \\
Male & $68(43.6 \%)$ \\
Female & $46(29.5 \%)$ \\
\hline AH: Grade 1 & $101(64.7 \%)$ \\
Grade 2 & $9(5.8 \%)$ \\
\hline Normal body weight, $\%$ & $9(5.8 \%)$ \\
Increased body weight, $\%$ & $41(26.3 \%)$ \\
Obesity, $\%$ & $106(67.9 \%)$ \\
\hline LDL cholesterol $>100 \mathrm{mg} / \mathrm{dl}$ & $129(82.7 \%)$ \\
\hline CHD (FC I-II) & $55(35.2 \%)$ \\
\hline T2DM & $21(13.5 \%)$ \\
\hline Smoking & $51(32.7 \%)$ \\
\hline LVH & $140(89.7 \%)$ \\
\hline LVDD & $128(82.1 \%)$ \\
\hline
\end{tabular}

After 6 months of therapy, a further decrease in the levels of SBP and DBP was observed, and the primary target BP level was achieved in another 29 patients. In total, against the background of the 6-month FDTC therapy at the indicated initial doses, the primary target BP level was achieved in $144(92.3 \%)$ patients and the recommended target BP level in $128(82.4 \%)$ patients. At the same time, SBP decreased by $-25.15 \pm 5.73 \%$ and DBP by $-22.8 \pm 6.44 \%$. By the end of the 6-month treatment, 12 patients who received full-dose SPTC of AHDs were characterized as TRH patients (Table 2).

According to ABPM data, the target BP levels were achieved in the average daily and daytime SBP and DBP. 
Table 2.

Clinical efficacy of the FDTC therapy at the initial doses in the general group of patients with AH

\begin{tabular}{|c|c|c|c|c|c|}
\hline Variable & $\begin{array}{l}\text { Before treatment } \\
\text { (1) }\end{array}$ & $\begin{array}{l}\text { After } 3 \text { months of } \\
\text { the FDTC therapy } \\
\text { (2) }\end{array}$ & $P_{1-2}$ & $\begin{array}{l}\text { After } 6 \text { months of } \\
\text { the FDTC therapy } \\
\text { (3) }\end{array}$ & $P_{1-3}$ \\
\hline $\mathrm{SBP}, \mathrm{mmHg}$ & $163.26 \pm 16.97$ & $128.7 \pm 9.65$ & 0.0001 & $123.17 \pm 7.67$ & 0.0001 \\
\hline $\mathrm{DBP}, \mathrm{mmHg}$ & $99.56 \pm 8.42$ & $81.48 \pm 7.37$ & 0.0001 & $77.53 \pm 5.26$ & 0.0001 \\
\hline $\mathrm{PP}, \mathrm{mmHg}$ & $63.69 \pm 14.06$ & $47.32 \pm 7.22$ & 0.0001 & $45.63 \pm 5.75$ & 0.0001 \\
\hline $\mathrm{SBPc}, \mathrm{mmHg}$ & $156.37 \pm 23.3$ & $142.0 \pm 17.7$ & 0.0001 & $130.86 \pm 15.5$ & 0.0001 \\
\hline DBPc, mmHg & $92.64 \pm 15.02$ & $86.1 \pm 13.6$ & 0.0001 & $85.34 \pm 11.4$ & 0.0001 \\
\hline $\mathrm{PPc}, \mathrm{mmHg}$ & $63.3 \pm 21.54$ & $55.7 \pm 16.52$ & 0.035 & $46.0 \pm 14.08$ & 0.001 \\
\hline $\mathrm{PWV}, \mathrm{m} / \mathrm{sec}$ & $10.62 \pm 2.36$ & $9.97 \pm 1.99$ & 0.028 & $9.4 \pm 1.8$ & 0.02 \\
\hline Average 24-h SBP, mmHg & $142.4 \pm 15.15$ & $129.7 \pm 14.46$ & 0.0001 & $126.87 \pm 12.07$ & 0.0001 \\
\hline Average 24-h DBP, mmHg & $86.86 \pm 11.19$ & $80.13 \pm 10.88$ & 0.0001 & $78.87 \pm 7.02$ & 0.0001 \\
\hline Average daytime SBP, $\mathrm{mmHg}$ & $144.0 \pm 16.26$ & $131.7 \pm 14.99$ & 0.0001 & $129.9 \pm 12.6$ & 0.0001 \\
\hline Average daytime $\mathrm{DBP}, \mathrm{mmHg}$ & $88.98 \pm 11.98$ & $82.42 \pm 11.12$ & 0.0001 & $81.31 \pm 9.0$ & 0.0001 \\
\hline Average nighttime SBP, $\mathrm{mmHg}$ & $134.8 \pm 16.98$ & $124.4 \pm 14.66$ & 0.0001 & $121.44 \pm 10.8$ & 0.0001 \\
\hline Average nighttime DBP, $\mathrm{mmHg}$ & $80.76 \pm 12.46$ & $74.29 \pm 10.8$ & 0.0001 & $74.56 \pm 6.65$ & 0.0001 \\
\hline LVM, g & $298.36 \pm 58.25$ & $255.84 \pm 68.36$ & 0.0001 & $247.03 \pm 69.7$ & 0.0001 \\
\hline LVMI, g/m² & $148.54 \pm 30.2$ & $128.7 \pm 29.7$ & 0.0001 & $125.5 \pm 30.85$ & 0.0001 \\
\hline $\mathrm{E} / \mathrm{A}$ & $0.81 \pm 0.25$ & $0.84 \pm 0.22$ & 0.26 & $0.9 \pm 0.24$ & 0.001 \\
\hline
\end{tabular}

Table 3.

Clinical and hemodynamic characteristics of patients with controlled and uncontrolled hypertension after 3 months of the FDTC therapy

\begin{tabular}{|c|c|c|c|}
\hline Параметры & $\begin{array}{l}\text { Patients with controlled } \\
\text { hypertension, } n=115\end{array}$ & $P$-value & $\begin{array}{l}\text { Patients with uncontrolled } \\
\text { hypertension, } n=41\end{array}$ \\
\hline SBP, mmHg & $158.7 \pm 15.23$ & 0.0001 & $173.87 \pm 16.34$ \\
\hline DBP, $\mathrm{mmHg}$ & $98.44 \pm 9.16$ & 0.053 & $103.1 \pm 7.2$ \\
\hline $\mathrm{PP}, \mathrm{mmHg}$ & $60.71 \pm 11.58$ & 0.0001 & $71.88 \pm 14.62$ \\
\hline $\mathrm{SBPc}, \mathrm{mmHg}$ & $149.5 \pm 22.54$ & 0.0001 & $173.78 \pm 32.67$ \\
\hline DBPc, mmHg & $91.95 \pm 15.23$ & 0.51 & $95.0 \pm 15.88$ \\
\hline PPc, mmHg & $57.24 \pm 18.1$ & 0.0001 & $77.55 \pm 32.87$ \\
\hline $\mathrm{PWV}, \mathrm{m} / \mathrm{sec}$ & $10.2 \pm 2.24$ & 0.003 & $12.12 \pm 2.88$ \\
\hline Average 24- h SBP, mmHg & $139.5 \pm 13.66$ & 0.002 & $151.4 \pm 18.2$ \\
\hline Average $24-\mathrm{h}$ DBP, mmHg & $85.54 \pm 10.4$ & 0.346 & $88.33 \pm 13.06$ \\
\hline Average daytime SBP, mmHg & $140.6 \pm 14.28$ & 0.003 & $152.2 \pm 18.24$ \\
\hline Average daytime DBP, $\mathrm{mmHg}$ & $87.49 \pm 10.97$ & 0.31 & $90.33 \pm 14.0$ \\
\hline Average nighttime SBP, mmHg & $132.5 \pm 16.36$ & 0.006 & $144.17 \pm 18.56$ \\
\hline Average nighttime DBP, $\mathrm{mmHg}$ & $80.25 \pm 13.08$ & 0.77 & $81.85 \pm 11.54$ \\
\hline LVM, g & $275.6 \pm 74.6$ & 0.044 & $303.2 \pm 75.5$ \\
\hline LVMI, $\mathrm{g} / \mathrm{m}^{2}$ & $138.27 \pm 30.7$ & 0.052 & $149.3 \pm 31.9$ \\
\hline $\mathrm{E} / \mathrm{A}$ & $0.83 \pm 0.25$ & 0.25 & $0.78 \pm 0.2$ \\
\hline
\end{tabular}


After 6 months of therapy, the average nighttime SBP and DBP decreased slightly, compared to 3-month data, but the target values were not achieved.

The echocardiography data showed a significant decrease in LVMI by $-9.7 \pm 7.3 \%$ after the 3-month treatment. After 6 months of treatment, there was a further decrease in LVMI up to $-13.5 \pm 10.1 \%$, while $34 \%$ of patients had no $\mathrm{LVH}$, according to LVMI. After the 6-month treatment, $\mathrm{LVH}$ remained in $65.4 \%$ of patients versus $89.7 \%$ before starting therapy. The 6-month dynamics of the LVDD indicator also slightly improved; LVDD was not determined in $25 \%$ of patients.

To identify predictors of insufficient BP control, we compared the baseline data of patients who achieved and did not achieve the primary target BP level. After 3 months of treatment with SPTC in the initial doses in groups with controlled and uncontrolled hypertension, the degree of SBP reduction was $-21.2 \pm 6.8 \%$ and $-16.54 \pm 7.8 \% \quad(P=0.008)$, respectively, and for DBP $-18.3 \pm 7.5 \%$ and $-12.62 \pm 7.66 \%$ $(P=0.0001)$, respectively. In the group of patients with $\mathrm{UCH}$ versus controlled hypertension, the number of patients with T2DM was significantly higher $(24.4 \%$ and $12.6 \%$, respectively, $[P<0.05])$.

A retrospective analysis of the hemodynamic data of patients before treatment revealed significantly high indicators for the office SBP, DBP, and PP, the central SBP, PWV, the average daily, daytime and nighttime SBP, and a higher LVMI and LVDD in patients with uncontrolled hypertension than in patients who achieved target blood pressure levels after 3 months of therapy (Table 3). The results obtained indicate the possibility of using a full-dose SPTC (Per/Ind/Aml and $\mathrm{Tel} / \mathrm{HCTZ} / \mathrm{Aml}$ ) at the start of treatment in patients with uncontrolled hypertension.

\section{Discussion}

Treatment-resistant hypertension affects between 3\% and $30 \%$ of hypertensive patients, and its presence is associated with increased cardiovascular morbidity and mortality. ${ }^{(9)}$ Among the reasons for poor hypertension control, the most important are inappropriate treatment regimens (no combination therapy, inadequate doses, or inappropriate combinations) and poor adherence to treatment. As is known, $\mathrm{PWV}>10 \mathrm{~m} / \mathrm{s}, 24-\mathrm{h} \mathrm{PP} \geq 63$ $\mathrm{mmHg}$, or central PP $>55 \mathrm{mmHg}$ suggests vascular remodelling. The absence of increased arterial stiffness suggests the presence of pseudo-resistance that suggests to search for poor treatment adherence, life-style factors known to increase arterial BP, and drugs interfering with antihypertensive therapy. ${ }^{(9)}$

A group of Russian and Norwegian scientists examined uncontrolled hypertension and differences in treatment regimens between a high-risk country, Russia, and a low-risk one, Norway, to gain a better understanding of the underlying factors. ${ }^{(10)}$ Population-based survey data on 40- 69-year-olds with hypertension were obtained from Know Your Heart Study (KYH, n=2284) performed in Russia (2015-2018), and the seventh wave of The Tromsø Study (Tromsø 7, n=5939) performed in Norway (2015-2016). Among all those with hypertension, regardless of treatment status, control of BP was achieved in $22 \%$ of men (KYH and Tromsø 7), while among women it was $33 \%$ in Tromsø 7 and $43 \%$ in KYH. When the analysis was limited to those on treatment for hypertension, the percentage of uncontrolled hypertension was higher in $\mathrm{KYH}$ (47.8\%, CI 95 44.6-50.9\%) than Tromsø 7 (38.2, 36.1-40.5\%). The corresponding figures for apparent treatment-resistant hypertension were $9.8 \%(8.2 \%-11.7 \%)$ and $5.7 \%(4.8-6.8 \%)$, respectively. Antihypertensive monotherapies were more common than combinations and used by $58 \%$ in Tromsø 7 and $44 \%$ in $\mathrm{KYH}$. The authors concluded that the factors associated with untreated hypertension overlap with known correlates of non-adherence to treatment and non-attendance at health checks. In contrast, apparent treatment-resistant hypertension was characterized by obesity and underlying comorbidities, potentially complicating treatment.

International guidelines for the treatment of arterial hypertension indicate that 2 regimens of therapy, depending on the initial cardiovascular risk, are capable of achieving the target blood pressure level: monotherapy and combination therapy. ${ }^{(6)}$ For hypertensive patients with a high cardiovascular risk, it is recommended to start combined drug treatment and a rapid dose increase. In the ACCOMPLISH study, 74\% of hypertensive patients with a high cardiovascular risk had already received 2 or more antihypertensive drugs at baseline prior to enrollment in the study. ${ }^{(11)}$

According to National Clinical Guideline Centre (UK), 1 in 5 hypertensive patients is on a combination of 3 or more antihypertensive drugs. In this case, the most commonly used combination consists of diuretics, ACEIs and CCBs, compared to other three-component combinations. ${ }^{(12)}$

According to the Health Survey for England (HSE), the most prescribed drugs in England (2011) were RAAS blockers $(53 \%)$, CCB $(20 \%)$, then diuretics $(15 \%)$, beta-blockers $(11 \%)$, and other drugs $(1 \%)$.At the same time, for tripleantihypertensive drug combinations, a combination of diuretics, ACEIs/ARBs and CCBs was more often prescribed than other triple combinations. ${ }^{(13)}$

According to a statement by the American Society of Hypertension and the International Society of Hypertension (2013), a triple combination of ACEI or ARB/CCB/diuretics in full or maximally tolerated doses is recommended for treatment of uncontrolled hypertension. ${ }^{(14)}$ The same approach to the choice of a triple combination of antihypertensive drugs is indicated in the $2018 \mathrm{ESH} / \mathrm{ESH}$ Guidelines with an emphasis on the choice of fixed-dose triple combination of antihypertensive drugs (ACEI or $\mathrm{ARB} / \mathrm{CCB} /$ diuretic in a single pill). ${ }^{(6)}$

As shown in the ADVANCE trial, in hypertensive patients with type 2 diabetes mellitus, the addition of CCBs against the background of treatment with indapamide and perindopril doubled both the antihypertensive efficacy and the effectiveness in reducing cardiovascular mortality from $14 \%$ to $28 \%$ in high-risk hypertensive patients. Even the use of a low-dose, triple combination of antihypertensive drugs made it possible to achieve the target blood pressure level, and a triple combination of $\mathrm{ACEI} / \mathrm{CCB} /$ diuretics in full or maximally tolerated doses normalized blood pressure in patients considered resistant to antihypertensive therapy. ${ }^{(15)}$ 
The PIANIST study showed that the single-pill triple combination containing Per/Ind/Aml was effectively and safely administered to a large population of high- and veryhigh-risk hypertensive patients who had not reached target office BP values with previous treatment. ${ }^{(16)}$

In a study performed by Nedogoda et al., ${ }^{(17)} \mathrm{AH}$ patients were randomly assigned to: single-pill triple combination of Per $(5 \mathrm{mg}) / \mathrm{Ind}(1.25 \mathrm{mg}) / \mathrm{Aml}(5 \mathrm{mg})$ or a dual-pill combination of Per $(5 \mathrm{mg}) / \mathrm{Ind}(1.25 \mathrm{mg})+\mathrm{Aml}(5 \mathrm{mg})$ once daily for 12 weeks. The primary endpoint was a change in office supine SBP and DBP from baseline to Week 12. At Week 12, both tripletherapy regimens were associated with clinically significant reductions in SBP, compared with baseline $(-21.5 \pm 11.7$ $\mathrm{mmHg}$ and $-20.0 \pm 12.9 \mathrm{mmHg}$, respectively) Reductions in office supine DBP were also clinically significant $(-15.3 \pm 7.8$ $\mathrm{mmHg}$ and $-14.8 \pm 9.0 \mathrm{mmHg}$, respectively). The majority of patients were treatment responders at Week 4 (89.2 and 82.9\%, respectively) and had achieved blood pressure control ( 87.8 vs. $78.6 \%$, respectively), which was maintained until Week 12 in both treatment groups. Both treatments were well tolerated with no between-group differences.

A study conducted by Mazza et al. ${ }^{(18)}$ compared the efficacy of fixed-dose triple combination of antihypertensive drugs with that of a free combination of 3 antihypertensives in patients with uncontrolled hypertension. Ninety-two patients with uncontrolled hypertension previously treated with an RAAS inhibitor plus HCTZ were switched to once-daily fixeddose triple combination therapy with Per/Ind/Aml(5-10/1.252.5/5-10 mg). Significant reductions in ambulatory 24-h, daytime and nighttime SBP, and PP were found in the fixeddose triple combination group, relative to reductions seen with free-combination therapy, after the first month only of followup. Target blood pressure values (mean 24-h ambulatory SBP/ DBP $<130 / 80 \mathrm{mmHg}$ ) were reached by more recipients of fixed-dose triple combination than free-combination therapy (64.8\% vs. $46.9 \%, P<0.05)$ at Month 4 of follow-up.

Of the fixed-dose triple combination, including ARBs, combinations of valsartan/olmesartan with HCTZ and amlodipine have been studied, which were approved by the European Medicines Agency in 2009. Stafylas et al. ${ }^{(19)}$ compared the cost-utility of the first available single-pill triple combination containing valsartan (Val), Aml and HCTZ, with each of the same components in dual combinations in patients with moderate to severe hypertension. A Markov model with eight health states was constructed. The short-term effect of antihypertensive therapy on BP was extrapolated through the Hellenic SCORE and Framingham risk equations, estimating the long-term survival and quality-adjusted life-years (QALYs) saved. The incremental cost-effectiveness ratio of the triple combination versus $\mathrm{Val} / \mathrm{Aml}$ and $\mathrm{Aml} / \mathrm{HCTZ}$ was far lower than the Greek GDP per capita and really close for $\mathrm{Val} / \mathrm{HCTZ}$, suggesting the $\mathrm{Val} / \mathrm{Aml} / \mathrm{HCTZ}$ combination to be cost-effective. The probability that the single-pill triple combination is cost-effective was more than $90 \%$. The authors concluded that a single-pill Val/Aml/HCTZ therapy is a cost-effective antihypertensive choice for the treatment of moderate to severe hypertension, compared to its dual components.
Telmisartan, like valsartan, is the most studied ARB in high-risk hypertensive patients with metabolic syndrome, type 2 diabetes mellitus, and nephropathy. Telmisartan is the most long-acting ARB available today. It is of interest to compare the effectiveness of this drug in lowering blood pressure with valsartan. Takagi et al. ${ }^{(20)}$ performed an updated meta-analysis of randomized controlled trials of telmisartan versus losartan therapy for reduction of ambulatory blood pressure in patients with arterial hypertension. The meta-analysis included a total of 2409 patients with hypertension. Pooled analysis suggested significant reductions in all of 24-h (mean differences of SBP/DBP, $-2.09 /-1.57 \mathrm{mmHg})$, last 6-h $(-2.96 /-2.15 \mathrm{mmHg})$, morning $(-2.71 /-2.37 \mathrm{mmHg})$, daytime $(-1.74 /-1.73 \mathrm{mmHg})$ and nighttime blood pressure $(-2.70 /-2.08 \mathrm{mmHg})$ among patients randomized to telmisartan versus losartan therapy. Thus, a statistically significant result favored telmisartan over losartan therapy.

Thus, according to the data of randomized clinical trials, the selected single-pill triple combinations based on the RAAS blockers, diuretics, and CCB were not inferior to each other and had high clinical efficacy. The selected combinations of Per/Ind/Aml and Tel/HCTZ/Aml are 2 of the desired rational combinations: Aml and diuretics have natriuretic and vasodilating actions, and Per/Tel blocks RAAS hyperactivity. Thus, the antihypertensive and organ-protective efficacy of drugs is potentiated, resulting in a decrease in morbidity and cardiovascular mortality. Complex treatment of patients with non-drug correction of risk factors and single-pill triple combination therapy makes it possible to reduce the number of patients with uncontrolled hypertension in whom the previous free-combination therapy with 2 and even 3 antihypertensive drugs was not effective.

The results of our study showed that the fixed-dose triple combination therapy at the indicated initial doses in patients with uncontrolled hypertension made it possible to achieve the primary target BP level in $73.7 \%$ of patients after 3 months of treatment. A further increase in single-pill triple combination doses made it possible to increase the number of patients who achieved the primary goal to $92.3 \%$, and the recommended goal in $82.4 \%$ of patients.

As shown by a comparative analysis of 3-month treatment, according to baseline data, 41 patients who did not reach the primary target BP level had significantly higher levels of the office SBP, DBP, and PP, central SBP, PWV, the average daily, daytime and nighttime SBP than patients $(\mathrm{n}=115)$ who achieved target BP levels. An increase in the dose of drugs to the maximum tolerable (Per/Ind/Aml $[10 \mathrm{mg} / 2.5 \mathrm{mg} / 10 \mathrm{mg}]$ and Tel/ HCTZ/Aml [80mg $/ 25 \mathrm{mg} / 10 \mathrm{mg}$ ], respectively), after 6 months of therapy, led to a further decrease in the levels of SBP and DBP, with the achievement of the primary target BP level in another 29 patients. The results obtained indicate the possibility of using a full-dose single-pill triple combination (Per/Ind/ $\mathrm{Aml}$ and $\mathrm{Tel} / \mathrm{HCTZ} / \mathrm{Aml}$ ) at the start of treatment in patients with uncontrolled hypertension. After 6 months of therapy, 12 patients who received full-dose single-pill triple combination treatment were characterized as patients with treatmentresistant hypertension, which required the addition of the fourth antihypertensive drug according to the recommendations. ${ }^{(6)}$ 


\section{Conclusion}

Despite the fact that our study was limited in the number of patients with uncontrolled hypertension and the duration of follow-up, a 6-month fixed-dose triple combination therapy (Per/Ind/Aml and Tel/HCTZ/Aml) in this study showed a high antihypertensive and cardio-protective efficacy, and a reliably positive effect on the daily blood pressure profile, central blood pressure, with a decrease in PWV and LVMI. Against the background of selected doses of single-pill triple combination, $92.3 \%$ of patients with uncontrolled hypertension reached the primary target blood pressure level $(<140 / 90 \mathrm{mmHg})$ and $82.4 \%$ of patients reached the recommended target blood pressure level $(<130 / 80 \mathrm{mmHg}) ; 7.7 \%$ of patients were diagnosed with treatment-resistant hypertension. Markers of uncontrolled hypertension are high SBP, DBP, and increased PWV, which requires the maximum doses of a full-dose single-pill triple combination of antihypertensive drugs, without wasting time on titration of drug doses.

\section{Competing Interests}

The authors declare that they have no competing interests.

\section{References}

1. Riley L, Guthold R, Cowan M, Savin S, Bhatti L, Armstrong T, Bonita R. The World Health Organization STEPwise Approach to Noncommunicable Disease RiskFactor Surveillance: Methods, Challenges, and Opportunities. Am J Public Health. 2016 Jan;106(1):74-8. doi: 10.2105/ AJPH.2015.302962.

2. Kurbanov R.D., Khamidullaeva G.A. Arterial hypertension. Monograph. Tashkent: "Noshirlik Yog'dusi"; 2017. [In Uzbek].

3. Khamidullaeva GA, Tursunova NB, Abdullaeva GZh, Masharipov ShM, et al. Identification of truly resistant hypertension and the effectiveness of multicomponent antihypertensive therapy. Trudnyi Pazient. 2019;17(11-12):611. \{Article in Russian].

4. Karpov IuA, Deev AD. [Uncontrolled arterial hypertension--new possibilities in solving problems of increasing the effectiveness of treatment]. Kardiologiia. 2012;52(2):29-35.[Article in Russian].

5. Carey RM, Calhoun DA, Bakris GL, Brook RD, Daugherty SL, Dennison-Himmelfarb CR, Egan BM, Flack JM, Gidding SS, Judd E, Lackland DT, Laffer CL, NewtonCheh C, Smith SM, Taler SJ, Textor SC, Turan TN, White WB; American Heart Association Professional/Public Education and Publications Committee of the Council on Hypertension; Council on Cardiovascular and Stroke Nursing; Council on Clinical Cardiology; Council on Genomic and Precision Medicine; Council on Peripheral Vascular Disease; Council on Quality of Care and Outcomes Research; and Stroke

*Corresponding author: Gulnoz A. Khamidullaeva, PhD, ScD. The Republican Specialized Center of Cardiology, Tashkent, Uzbekistan.E-mail: gulnoz0566@mail.ru
Council. Resistant Hypertension: Detection, Evaluation, and Management: A Scientific Statement From the American Heart Association.Hypertension. 2018 Nov;72(5):e53-e90. doi: 10.1161/HYP.0000000000000084.

6. Williams B, Mancia G, Spiering W, Agabiti Rosei E, Azizi M, Burnier M, Clement DL, Coca A, de Simone G, Dominiczak A, Kahan T, Mahfoud F, Redon J, Ruilope L, Zanchetti A, Kerins M, Kjeldsen SE, Kreutz R, Laurent S, Lip GYH, McManus R, Narkiewicz K, Ruschitzka F, Schmieder RE, Shlyakhto E, Tsioufis C, Aboyans V, Desormais I; ESC Scientific Document Group. 2018 ESC/ESH Guidelines for the management of arterial hypertension. Eur Heart J. 2018 Sep 1;39(33):3021-3104. doi: 10.1093/eurheartj/ehy339. Erratum in: Eur Heart J. 2019 Feb 1;40(5):475.

7. Voigt JU, Pedrizzetti G, Lysyansky P, Marwick TH, Houle H, Baumann R, Pedri S, Ito Y, Abe Y, Metz S, Song JH, Hamilton J, Sengupta PP, Kolias TJ, d'Hooge J, Aurigemma GP, Thomas JD, Badano LP. Definitions for a common standard for 2D speckle tracking echocardiography: consensus document of the EACVI/ASE/Industry Task Force to standardize deformation imaging. Eur Heart J Cardiovasc Imaging. 2015 Jan;16(1):1-11. doi: 10.1093/ehjci/jeu184.

8. Devereux RB, de Simone G, Ganau A, Roman MJ. Left ventricular hypertrophy and geometric remodeling in hypertension: stimuli, functional consequences and prognostic implications. J Hypertens Suppl. 1994;12(10):S117-27.

9. Rimoldi SF, Messerli FH, Bangalore S, Scherrer U. Resistant hypertension: what the cardiologist needs to know. Eur Heart J. 2015 Oct 21;36(40):2686-95. doi: 10.1093/ eurheartj/ehv392.

10. Petersen J, Malyutina S, Ryabikov A, Kontsevaya A, Kudryavtsev AV, Eggen AE, McKee M, Cook S, Hopstock LA, Schirmer H, Leon DA. Uncontrolled and apparent treatment resistant hypertension: a cross-sectional study of Russian and Norwegian 40-69 year olds. BMC Cardiovasc Disord. 2020 Mar 13;20(1):135. doi: 10.1186/s12872-020-01407-2.

11. Bakris GL, Sarafidis PA, Weir MR, Dahlöf B, Pitt B, Jamerson K, Velazquez EJ, Staikos-Byrne L, Kelly RY, Shi V, Chiang YT, Weber MA; ACCOMPLISH Trial investigators. Renal outcomes with different fixed-dose combination therapies in patients with hypertension at high risk for cardiovascular events (ACCOMPLISH): a prespecified secondary analysis of a randomised controlled trial. Lancet. 2010 Apr 3;375(9721):1173-81. doi: 10.1016/S01406736(09)62100-0.

12. National Clinical Guideline Centre (UK). Hypertension: The Clinical Management of Primary Hypertension in Adults: Update of Clinical Guidelines 18 and 34 [Internet]. London: Royal College of Physicians (UK); 2011 Aug.

13. Falaschetti E, Mindell J, Knott C, Poulter N. Hypertension management in England: a serial cross-sectional study from 1994 to 2011. Lancet. 2014 May 31;383(9932):1912-9. doi: 10.1016/S0140-6736(14)60688-7.

14. Weber MA, Schiffrin EL, White WB, Mann S, Lindholm LH, Kenerson JG, Flack JM, Carter BL, Materson BJ, Ram CV, Cohen DL, Cadet JC, Jean-Charles RR, Taler S, Kountz D, Townsend RR, Chalmers J, Ramirez AJ, Bakris GL, Wang J, Schutte AE, Bisognano JD, Touyz RM, Sica D, Harrap SB. Clinical practice guidelines for the management of hypertension in the community: a statement by the American Society of Hypertension and the International Society of Hypertension. J Clin Hypertens (Greenwich). 2014 Jan;16(1):14-26. doi: 10.1111/jch.12237. 
15. Patel A; ADVANCE Collaborative Group, MacMahon S, Chalmers J, Neal B, Woodward M, Billot L, Harrap S, Poulter N, Marre M, Cooper M, Glasziou P, Grobbee DE, Hamet P, Heller S, Liu LS, Mancia G, Mogensen CE, Pan CY, Rodgers A, Williams B. Effects of a fixed combination of perindopril and indapamide on macrovascular and microvascular outcomes in patients with type 2 diabetes mellitus (the ADVANCE trial): a randomised controlled trial. Lancet. 2007 Sep 8;370(9590):829-40.doi: 10.1016/S01406736(07)61303-8.

16. Tóth K; PIANIST Investigators. Antihypertensive efficacy of triple combination perindopril/indapamide plus amlodipine in high-risk hypertensives: results of the PIANIST study (Perindopril-Indapamide plus AmlodipiNe in high rISk hyperTensive patients). Am J Cardiovasc Drugs. 2014 Apr;14(2):137-45. doi: 10.1007/s40256-014-0067-2. Erratum in: Am J Cardiovasc Drugs. 2014 Jun;14(3):239.

17. Nedogoda SV, Stojanov VJ. Single-Pill Combination of Perindopril/Indapamide/Amlodipine in Patients with
Uncontrolled Hypertension: A Randomized Controlled Trial. Cardiol Ther. 2017 Jun;6(1):91-104. doi: 10.1007/s40119017-0085-7.

18. Mazza A, Lenti S, Schiavon L, Sacco AP, Dell'Avvocata F, Rigatelli G, Ramazzina E. Fixed-Dose Triple Combination of Antihypertensive Drugs Improves Blood Pressure Control: From Clinical Trials to Clinical Practice. Adv Ther. 2017 Apr;34(4):975-985. doi: 10.1007/s12325-017-0511-1.

19. Stafylas P, Kourlaba G, Hatzikou M, Georgiopoulos D, Sarafidis P, Maniadakis N. Economic evaluation of a singlepill triple antihypertensive therapy with valsartan, amlodipine, and hydrochlorothiazide against its dual components. Cost Eff Resour Alloc. 2015 Jun 9;13:10. doi: 10.1186/s12962-0150036-x.

20. Takagi H, Niwa M, Mizuno Y, Goto SN, Umemoto T; AllLiterature Investigation of Cardiovascular Evidence Group. A meta-analysis of randomized trials of telmisartan versus losartan for reduction of ambulatory blood pressure. Hypertens Res. 2013 Nov;36(11):959-66. doi: 10.1038/hr.2013.78. 